\title{
Comment on "Study of mixed-mode oscillations in a nonlinear cardiovascular system" [Nonlinear Dyn, doi: 10.1007/s11071-020-05612-8]
}

\author{
Wieslaw Marszalek $\mathbb{D}$
}

Received: 27 May 2020 / Accepted: 1 September 2020 / Published online: 11 September 2020

(C) Springer Nature B.V. 2020

\begin{abstract}
This note comments on the questionable approach and claims made in "Study of mixed-mode oscillations in a nonlinear cardiovascular system" [Nonlinear Dyn, doi: 10.1007/s11071-020-05612-8]. Although the author of the above paper attempts to discuss a nonlinear cardiovascular system and its dynamics, the conductance model used, is that of the wellknown Cassie-Mayr model of electric arcs, known in the literature since the 1940s. No reference to that wellknown model is made however. Moreover, the claim that the conductance model is taken "from the data of a large patient population" is baseless and has no grounds in reality. Thus, an extreme caution is advised, when analyzing the time responses and properties of the nonlinear model in the commented paper. It is questionable that they represent quantities of a human cardiovascular system.
\end{abstract}

\section{Introduction: the COVID-19 modeling fiasco}

Mathematical modeling of nonlinear dynamical systems is an interesting area of research that attracts many researchers, sometimes coming into a particular area from a completely different field. This may yield an outcome that is unacceptable to experts and the results that are questionable or even being out of touch with

W. Marszalek $(\bowtie)$

Institute of Computer Science, Opole University of

Technology, 45-758 Opole, Poland

e-mail:w.marszalek@po.edu.edu the real world. The very recent COVID-19 modeling by a pandemic computer modeler from Imperial College London [1] was rebuffed by experts on epidemiology [2] as unreliable, unverifiable, and, frankly, useless. The modeler is not advising the UK Prime Minister anymore about the COVID-19 pandemic and was nicknamed "prof. Lockdown" by the media [3].

\section{Model in [4] does not pass the credibility test}

The peripheral conductance equation (model) given in [4, formula (5)] is assumed to be appropriate to be incorporated in a model of nonlinear cardiovascular system. That model claimed to be "from the data of a large patient population" is, in fact, the model originated about 80 years ago by Cassie [5] and Mayr [6], who studied the dynamics of electrical arcs rather than cardiovascular systems. Long time ago, the two separate models of Cassie and Mayr have converged into one model, the Cassie-Mayr one. The literature on Cassie-Mayr model is immense, see $[7,8]$ and the references therein. ${ }^{1}$ An extensive literature search of

\footnotetext{
${ }^{1}$ Quote from [9]: "The literature on electric arcs in welding, foundry, gas discharge lamps, lighting as well as voltaic, iron, cobalt, nickel, titanium, and mercury arcs is particularly immense over the last 200 years. While the first results on electric arcs were published in the first part of the 1800s (...), they continued to appear throughout the 1900 s (... ). The new results on improved arc models are still being published in the electrical engineering literature (...). A list of papers on the topic of electric arcs available in the literature is really a very impressive and long one."
} 
published papers on the dynamics on cardiovascular models returns no reports that $[4$, formula (5)] is used to model conductance of cardiovascular systems, disapproving the claim made in [4] that the conductance model comes from a "large patient population."

Even more intriguing is the fact that $[4$, formula (5)] and the whole description of the parameters there is identical to the same model the author of [4] used in the paper he co-authored on electric arcs [9]. See there the text beginning with "Consider the Cassie-Mayr hybrid model of electric arcs ..." and ending with"... no energy dissipation occurs due to plasma radiation," including the following formula

$g=G_{\min }+\left[1-\mathrm{e}^{-\frac{i^{2}}{I_{0}^{2}}}\right] \frac{u i-K i^{2}}{U_{\mathrm{C}}^{2}}+\mathrm{e}^{-\frac{i^{2}}{I_{0}^{2}}} \frac{i^{2}}{P_{\mathrm{M}}}-\theta \frac{\mathrm{d} g}{\mathrm{~d} t}$

which is equivalent to [4, formula (5)] after rebranding of variables.

When a new model is proposed, a thoughtful approach is needed and a detailed derivation of that model should be shown, based on the existing definitions of quantities used, and physical laws obeyed by those quantities. A cardiovascular model that pops up in [4] without such a derivation, and most importantly, the model being "borrowed" without any proof of validity from a completely different field of electric arcs does not pass the test of credibility and acceptability.

\section{A brief summary}

Unreliable, unproven and ad hoc created models and data used in those models have little to no value in any field of engineering and science. The model in [4] certainly is of very questionable value. "Borrowing" the same equation (model) from one field and claiming it comes "from the data of a large patient population" without providing a shred of evidence is not acceptable. Because of that and the fact that the conductance model is an integral part of the whole nonlinear system in [4], the results presented in that paper should be approached with an extreme caution.

\section{Compliance with ethical standards}

Conflict of interest The author declares that he has no conflict of interest.

\section{References}

1. Ferguson, N.M., et al.: Impact of non-pharmaceutical interventions (NPIs) to reduce COVID-19 mortality and healthcare demand. Imperial College COVID-19 Response Team Report 9 (2020). https://spiral.imperial.ac.uk:8443/handle/ 10044/1/77482

2. Lewis, N.: Imperial College UK COVID-19 numbers don't seem to add up, Climate Etc. (2020). https://judithcurry.com/2020/04/01/imperial-college-uk-covid -19-numbers-dont-seem-to-add-up/

3. Daily News (2020). https://www.dailymail.co.uk/news/article$8327641 /$ Coronavirus-modelling-Professor-Neil-Fergusonbranded-mess-experts.html

4. Trzaska, Z.: Study of mixed-mode oscillations in a nonlinear cardiovascular system. Nonlinear Dyn (2020). https://doi. org/10.1007/s11071-020-05612-8

5. Cassie, A.M.: Arc Rupture and Circuit Serverity: A New Theory, vol. 102. CIGRE, Paris (1939)

6. Mayr, O.: Beiträge zur theorie des statischen und des dynamischen lichtbogens. Arch. Elektrotech. 37(12), 588608 (1943)

7. Tseng, K.-J., Wang, Y., Vilathgamuwa, D.M.: An experimentally verified hybrid Cassie-Mayr electric arc model for power electronics simulations. IEEE Trans. Power Electron. 12(3), 429-436 (1997). https://doi.org/10.1109/63.575670

8. Golestani, S., Samet, H.: Generalised Cassie-Mayr electric arc furnace models. IET Gener. Transm. Distrib. 10, 3364 3373 (2016). https://doi.org/10.1049/iet-gtd.2016.0405

9. Marszalek, W., Trzaska, Z.: Dynamical models of electric arcs and memristors: the common properties. IEEE Trans. Plasma Sci. 45, 259-265 (2017). https://doi.org/10.1109/TPS.2016. 2645879

Publisher's Note Springer Nature remains neutral with regard to jurisdictional claims in published maps and institutional affiliations. 